\title{
Aplikasi Alarm Anti Maling Berbasis Mikrokontroler AT Mega 8535
}

\author{
Edi Setiawan \\ Jurusan Teknik Informatika, Program Studi Sistem Informasi \\ Fakultas Teknik Universitas Negeri Gorontalo \\ edi.setiawan.79888@gmail.com
}

\begin{abstract}
Abstrak- Perkembangan Teknologi sekarang ini sangat membantu aktivitas manusia dalam kegiatan seharihari.Contohnya, dalam pengamanan benda berharga, rumah, kebun, dan sebagainya, banyak orang menggunakan kemajuan teknologi seperti kamera pengawas atau CCTV. Bahkan penggunaan CCTV telah menyebar hingga ke berbagai pelosok negeri. Namun sayangnya, kemajuan teknologi CCTV sekalipun bahkan tidak mampu menghentikan aksi pencurian. Bahkan seringkali CCTV di manipulasi oleh pelaku pencurian agar tidak merekam aksi mereka. Walaupun terekam CCTV sekalipun banyak kasus pencurian yang tidak mampu dicegah karena lambannya penanganan. Selain itu diperlukan pemantauan 24 jam penuh oleh petugas keamanan untuk menatap monior CCTV agar mampu menjaga keadaan. Hal ini tentu membebani pengguna yang mempunyai aktifitas dengan jadwal yang padat. Karena itu disini teknologi canggih seperti mikrokontroler memegang peranan yang sangat penting. Dalam hal ini misalnya mikrokontroler AT-mega 8535. Mikrokontroler mampu di ubah menjadi sebuah alat alarm anti- maling yang memiliki kemampuan untuk mendeteksi objek yang mencurigakan dan memberikan peringatan dengan cepat melalui SMS dan melakukan panggilan ke ponsel pengguna dimanapun dia berada dengan memadukan kecanggihan sensor ultrasonic, sensor PIR, dan modem Fasttrack. Dengan alat ini pengguna tidak akan merasa khawatir dan bisa beraktifitas dengan tenang. , Alat Alarm ini diharapkan mampu menjadi teknologi yang membantu kehidupan manusia dalam kehidupan sehari-hari terutama dalam hal pengawasan keamanan tempat tinggal maupun tempat penyimpanan benda berharga.
\end{abstract}

Kata Kunci-Alarm, Sensor Ultrasonik, Sensor PIR, modem fasttrack, CCTV, pencurian, Mikrokontroler At-mega 8535

\section{Pendahuluan}

Perkembangan teknologi saat ini mendorong manusia untuk terus berpikir kreatif, tidak hanya menggali penemuan penemuan baru, tapi juga memaksimalkan kinerja teknologi yang ada untuk meringankan kerja manusia dan menutupi kelemahan teknologi yang telah ada dalam kehidupan sehari hari seperti alarm anti maling

Pada saat ini, keamanan tempat tinggal, atau tempat penyimpanan barang berharga di serahkan pada petugas keamanan, cctv dan sebagainya. Banyak yang memilih cctv sebagai solusi keamanan karena dinilai lebih ekonomis dan praktis. CCTV di pasang disetiap sudut rumah agar dapat dipantau 24 jam penuh.
Namun, mulai bermunculan masalah terhadap CCTV diantaranya, dibutuhkan keahlian untuk melakukan instalasi CCTV, CCTV tidak mampu menghentikan pencurian walaupun mereka kejadian yang ada, mudah dimanipulasi oleh pelaku misalnya memutar CCTV dan sebagainya.

Masalah ini menjadi semakin besar dengan munculnya Undang Undang ITE pasal 27 dan 31. Dimana isinya antara lain penggunaan CCTV secara illegal dapat menerima denda sebesar 3 Miliyar serta hukuman penjara selama 9 tahun. Ini mulai di munculkan pada sebuah persidangan di Indonesia dimana CCTV yang digunakan untuk merekam suatu kejadian tidak dapat dijadikan alat bukti dan justru membuat pihak pelapor mendapatkan sanksi atas perekaman secara diam diam.

Berdasarkan masalah diatas, maka ditawarkan solusi untuk membantu CCTV, yaitu alarm ultrasonic berbasis Microcontroller . Dimana ini merupakan penambahan terhadap alarm anti maling yang sudah ada namun lebih ditingkatkan dalam hal pengamanan dan pendeteksian pelaku pencurian.

Permasalahan yang ingin diselesaikan adalah permasalahan yang timbul karena kelemahan CCTV, banyaknya resiko pencurian yang terjadi walaupun sudah terekam CCTV, lambannya respon atas kasus pencurian, banyak kasus pencurian yang tidak terpecahkan, membuat alarm berbasis mikrokonroler yang dapat mencegah terjadinya pencurian dengan respon pemberitahuan yang cepat jarak jauh, dan melakukan ujicoba pada alarm berbasis mirkrokontroler agar alarm dapat mendeteksi objek secara akurat dan memberikan peringatan dengan cepat ke penerima dimanapun dia berada. Tujuan dari penelitian ini adalah mengembangkan sebuah alat berupa alarm anti-maling yang menggunakan sensor ultrasonik berbasis mikrokontroler. Sehingga didapat manfaat dari alarm anti - maling ini adalah membantu menjaga keamanan ruangan atau benda berharga dengan bantuan mikrokontroler dimana pengguna akan diberi peringatan seketika apabila sensor mendeteksi keberadaan manusia dimanapun pengguna berada lewat pesan singkat (SMS) dan panggilan ke ponsel pengguna.

\section{Metode Penelitian}

\section{A. Perencanaan}

\section{1) Teknik Pengumpulan Data}

Teknik pegumpulan data ini menggunakan studi literature. Studi Literatur adalah mencari referensi teori 
yang relevan dengan kasus atau permasalahan yang ditemukan. Referensi dapat dicari dari buku, jurnal, artikel laporan penelitian, dan sius- situs di internet. Output daari studi literatur adalah terelokasinya referensi yang relevan dengan perumusan masalah.

\section{2) Studi Kelayakan}

Studi kelayakan digunakan untuk mengetahui manfaat ekonomis proyek perencanaan alarm anti maling berbasis mikrokontroler.

\section{B. Analisis Sistem}

Analisis sistem dilakukan untuk memberikan arahan dan menetukan tahap proses pengerjaan dalam hal penentuan kebijakan . Analisis sistem dilakukan dengan tahap sebagai berikut :

\section{1) Analisis Masalah}

Pada tahap ini dilakukan untuk mengetahui masalah yang sedang terjadi pada sistem lama atau sistem yang sedang berjalan.

\section{2) Analisis Kebutuhan}

Pada tahap ini mengetahui kebutuhan perangkat keras dan perangkat lunak yang digunakan.

\section{3) Analisis Kelayakan}

Berdasarkan pada tahap analisis kebutuhan bahwa pada tahap ini menjelaskan apakah sistem yang dibuat layak atau tidak untuk dilanjutkan, baik dari segi kelayakan maupun operasional.

\section{4) Analisis Sistem Berjalan}

Pada tahap ini dilakukan untuk mengetahui sistem atau proses yang sedang berjalan, digambarkan dalam activity diagram dan use case.

\section{Perancangan Sistem}

Perancangan sistem adalah merancang sistem secara rinci berdasarkan hasis analisis sistem yang ada, sehingga menghasilkan model baru yang diusulkan. Perancangan sistem dilakukan dengan tahap sebagai berikut :

\section{1) Perancangan perangkat keras}

Perancangan perangkat keras mengunakan skematika alat yang digunakan untuk membangun alat, gambar rancangan alat, diagram blok dan komponen diagram.

\section{2) Perancangan perangkat lunak}

Pada tahap ini terdiri dari flowchart dari algoritma yang digunakan oleh pengguna flowchart digunakan sebagai penjelas dalam menggambarkan urutan proses pada aplikasi. Sedangkan algoritma digunakan untuk mempermudah dalam pembuatan dan perencanaan suatu program.

\section{Implementasi}

Pada tahap ini adalah proses memaparkan hasil dari instalasi perangkat keras, langkah - langkah instalasi perangkat lunak, tampilan layar dari pengujian. Pada tahap pengujian, dilakukan ujicoba terhadap aplikasi. Kemudian hasil dari uji coba tersebut dievaluasi. Apabila terdapat kesalahan atau kekurangan pada aplikasi tersebut, maka dapat dilakukan perbaikan yang diperlukan .

1) Instalasi Perangkat Keras

Pada tahap ini akan dibahas tahapan dalam instalasi perangkat keras alarm anti - maling berbasis mikrokontroler.

\section{2) Instalasi Perangkat Lunak}

Pada tahap ini akan dijelaskan tahapan instalasi perangkat lunak yang dibutuhkan dalam pembuatan alarm anti- maling berbasis mikrokontroler.

\section{3) Pengujian}

Pada tahap ini akan dipaparkan hasil dari pengujian yang dilakukan terhadap alarm anti- maling agar dapat dikembangkan dimasa yang akan datang menjadi alat yang jauh lebih baik.

\section{a) Identifikasi dan Rencana Pengujian}

Pada tahap ini akan dibahas jenis pengujian yang akan digunakan ,kelas uji, butir uji dan tingkat pengujian yang dilakukan.

\section{b) Deskripsi dan Hasil Pengujian}

Pada tahap ini akan dibahas hasil dari pengujian yang dilakukan terhadap masing masing butir uji yang telah ditentukan sebelumnya bersama dengan tampilan hasil peringatan sms dan panggilan sebagai bentuk keluaran dari alarm anti- maling berbasis mikrokontroler.

\section{Pembahasan}

\section{A. Analisis Sistem}

Bab ini akan membahas mengenai masalah yang dihadapi, strategi penyelesaian dan penyelesaian masalah yang dicapai. Pada bab ini juga dijabarkan mengenai implementasi serta kekurangan dan kelebihan dan perangkat lunak yang dikembangkan.

\section{1) Analisis Masalah}

Adapun analisis masalah pada penilaian ini adalah penyajian informasi mengenai perancangan alarm anti maling berbasis mikrokontroler sebagai sarana pengamanan alternatif maupun tambahan pengamanan yang sudah ada.

Analisis masalah merupakan salah satu tahapan yang paling penting pada perancangan alarm anti -maling berbasis mikrokontroler, karena kesalahan didalam tahap ini akan menyebabkan kesalahan ditahap selanjutnya. 
Dalam tahap analisis masalah terdapat langkahlangkah dasar yang harus dilakukan untuk menemukan permasalahan dan kebutuhan alarm anti- maling berbasis mikrokontroler, langkah- langkah tersebut antara lain sebagai berikut.

\section{2) Analisis Kebutuhan}

Dari hasil analisa masalah yang didapat adalah dengan menggunakan sensor ulrasonik, sensor PIR, dan mikrokontroler, serta dipadukan dengan modem fast track, dapat menciptakan sebuah alat sistem keamanan canggih dimana dapat mendeteksi keberadaan manusia di ruang lingkup tertentu dan memberikan peringatan jarak jauh kepada user baik lewat pesan singkat (SMS) maupun panggilan melalui handphone.

Oleh karena itu perancangan alarm anti - maling berbasis mikrokontroler membutuhkan perangkat keras dan perangkat lunak yang mendukung. Perangkat keras dan perangkat lunak yang dibutuhkan dari sisi perangkat kerasa adalah Laptop, Mikrokontroler AT Mega 8535, Sensor ultrasonik HC- SRF04, Sensor PIR (Passive Infrared Reciever), Modem fast Track Wavecom. Sedangkan dari sisi perangkat lunak yang dibutuhkan adalah Sistem Operasi.

\section{3) Analisis Kelayakan}

Analisis kelayakan bertujuan untuk menilai suatu tahapan pembuatan sistem yang akan dibuat, sekaligus mengetahui apakah sistem tersebut layak atau tidak dijalankan. Pada proses penilaian tersebut dibagi menjadi beberapa aspek yang membutuhkan pertimbangan tertentu untuk memutuskannya.

Analisis kelayakan ini bertujuan untuk mempelajari bagaimana sebuah alarm anti- maling berbasis mikrokontroler dapat mendeteksi keberadaan orang pada jarak tertentu dan memberi peringatan jarak jauh melalui sms maupun panggilan melalui pesawat telpon sesuai perintah program yang telah diberikan.

\section{a) Kelayakan Teknologi}

Secara teknologi, perangkat ini layak digunakan karena teknologi yang digunakan merupakan penngembangan alarm anti- maling yang sudah ada dengan menambahkan beberapa sensor tambahan lalu menggabungkannya dengan modem fasttrack, dengan menggunakan mikrokontroler ATmega 8535 sebagai komponen utamanya.

Alat ini juga inovatif karena tidak membebani penggunanya untuk terus memantau keadaan tempat tinggal atau tempat barang beharga dan sebagainya terus - menerus.

\section{b) Kelayakan Operasional}

Dari segi kelayakan operasional, alat yang dibuat ini mempunyai pengoperasian yang sangat mudah. Sehingga orang awam sekalipun bisa menggunakannya dengan mudah.

\section{4) Analisis Sistem Berjalan}

Alarm anti- maling berbasis mikrokontroler sebenarnya telah banyak dibuat sebelumnya. Cara kerjanya memanfaatkan sensor ultrasonik sehingga apabila ada objek yang berada dalam jangkauan sensor ultrasonik, maka mikrokontroler akan memerintahkan buzzer untuk mengeluarkan suara.

Namun, alarm ini memiliki setidaknya 2 kelemahan fatal. Yang pertama adalah sensor ultrasonik tidak mampu membedakan objek yang didekatnya. Jadi sekalipun hanya benda mati, maka akan dianggap sebagai ancaman. Yang kedua, suara yang dihasilkan tidak akan berguna apabila ruangan dalam keadaan kosong, dan membuat pencuri menyadari alarm yang ada.

5) Activity Diagram Alarm Anti Maling Berbasis Mikrokontroler

Berikut activity diagram dari alarm anti maling berbasis mikrokontroler :

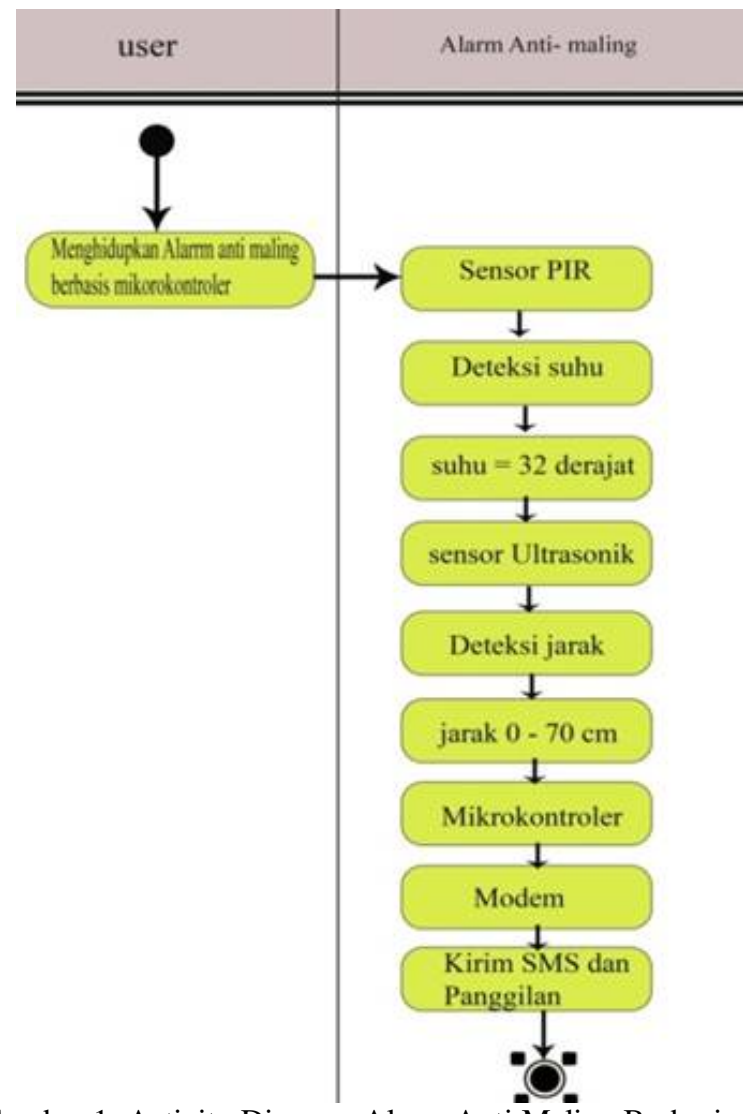

Gambar 1. Activity Diagram Alarm Anti Maling Berbasis Mikrokontroler

6) Deployment Diagram Alarm Anti Maling Berbasis Mikrokontroler

Pada rancangan alarm anti maling berbasis mikrokontroler di gambarkan pula deployment diagram seperti gambar dibawah ini : 


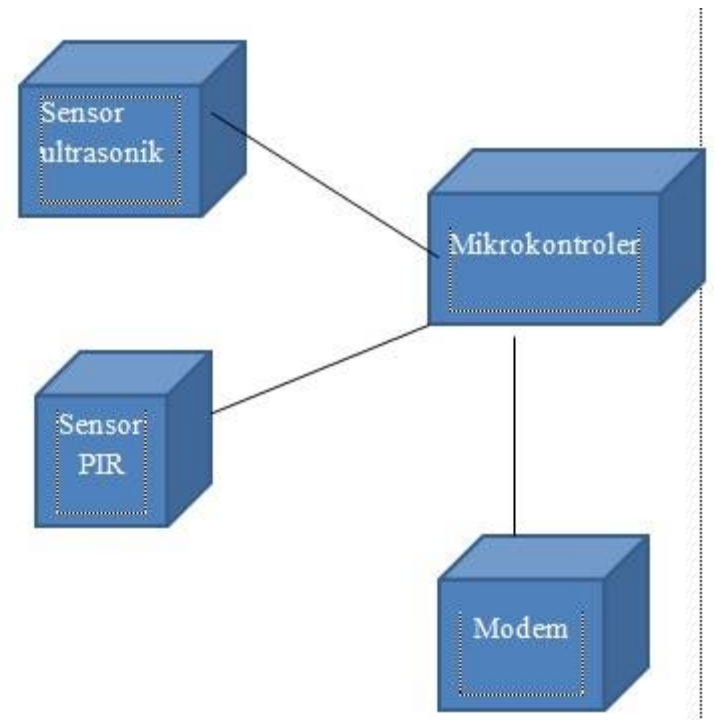

Gambar 2. Deployment Diagram Tongkat Tuna Netra Berbasis Mikrokontroler

7) Diagram Blok Alarm Anti Maling Berbasis Mikrokontroler

Berikut diagram blok dari alarm anti maling berbasis mikrokontroler :

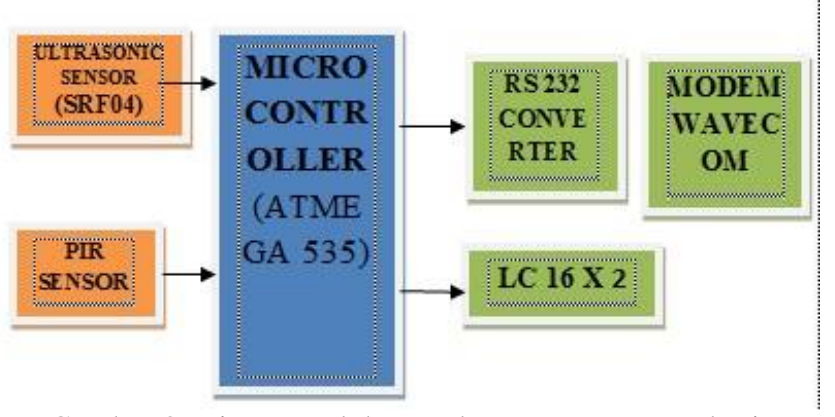

Gambar 3. Diagram Blok Tongkat Tuna Netra Berbasis Mikrokontroler

Keseluruhan diagram blok tersebut akan menghasilkan suatu sistem yang dapat berfungsi atau dapat bekerja sesuai dengan perancangan. Dari gambar diatas dapat dilihat bahwa pada rangkaian alarm anti- maling berbasis mikrokontroler terdiri dari beberapa bagian, yaitu :

- Sensor PIR

- Sensor ultrasonic HC- SRF04

- Mikrokontroler ATmega 8535

- Lcd Monitor 2 x 16

- RS-232 Conventer

- Modem Fast- Track Wavecom

8) Component Diagram Alarm Anti Maling Berbasis Mikrokontroler

Berikut ini component diagram dari alarm anti maling berbasis mikrokontroler :

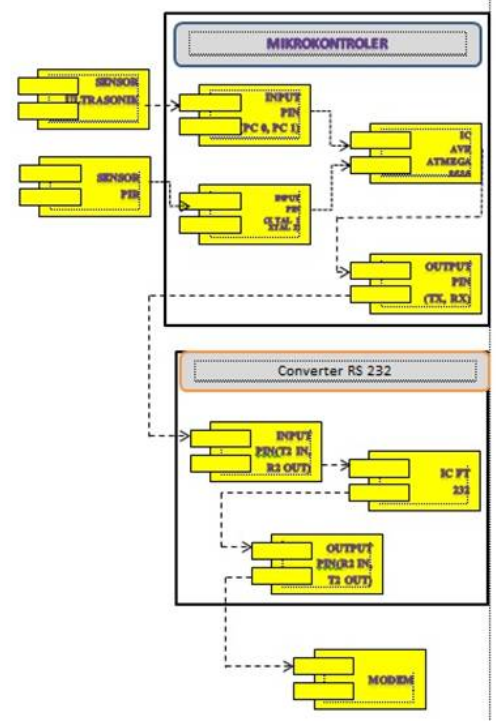

Gambar 4. Component Diagram Alarm Anti Maling Berbasis Mikrokontroler

9) Flowchart Alarm Anti Maling Berbasis Mikrokontroler Sebelum ketahap berikutnya, maka terlebih dahulu dibuatlah flowchart alarm anti- maling, dimulai dari pembacaan inframerah oleh sensor PIR, kemudian dilanjutkan dengan pembacaan jarak oleh sensor ultrasonik yang kemudian memberikan perintah pada mikrokontroler untuk mengirimkan peringatan melalui sms dan panggilan telpon. Penjelasan tersebut dapat dilihat melalui flowchart berikut ini :

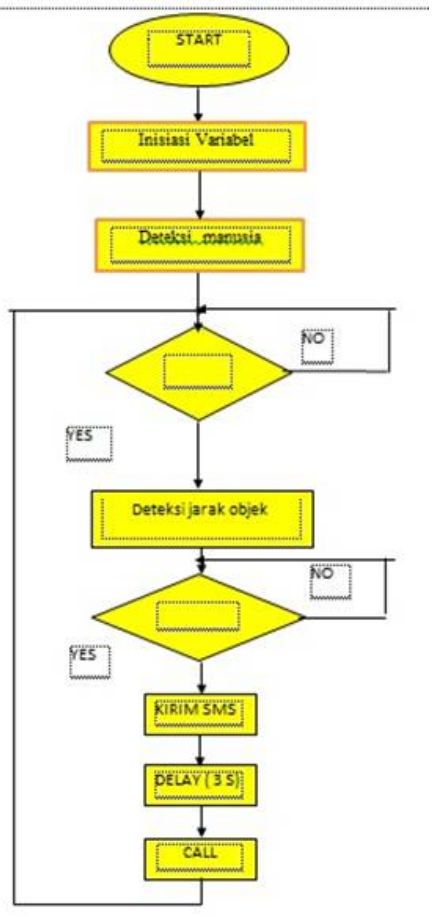

Gambar 5. Flowchart Tongkat Tuna Netra Berbasis Mikrokontroler 
10) Algoritma Tongkat Tuna Netra Berbasis Mikrokontroler

Perintah menjalankan program, akan dimulai ketika sensor PIR membaca objek dengan pancaran gelombang inframerah dan terdeteksi sebagai manusia maka program akan mulai berjalan:

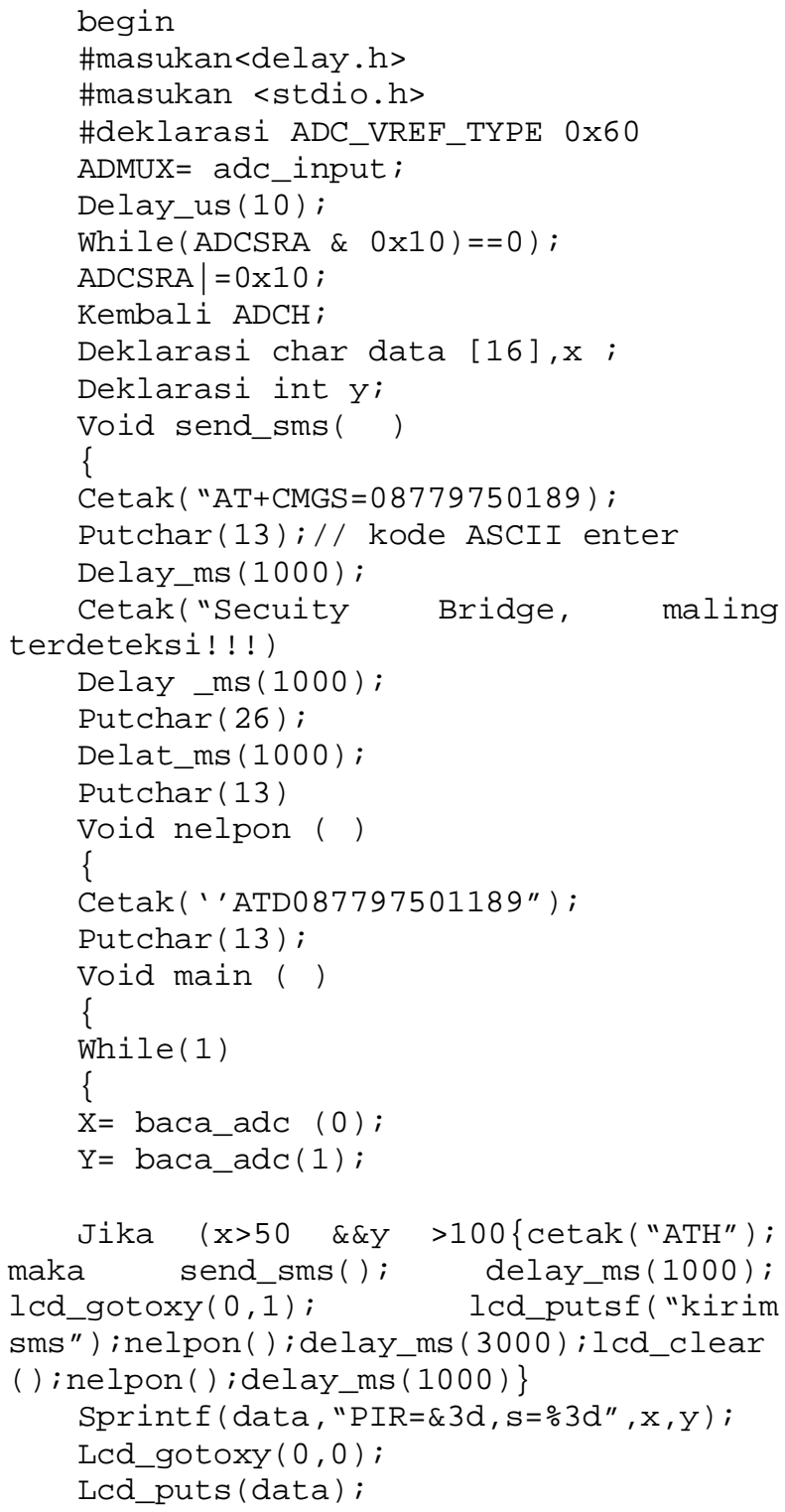

\section{B. Implementasi}

\section{1) Tampilan Rangkaian Sensor Ultrasonik Alarm Anti Maling Berbasis Mikrokontroler \\ Setelah melakukan rancangan rankaian sensor, maka tahap selanjutnya yaitu menghubungkan alat dengan mikrokontroler ATmega 8535 seperti gambar rangkaian yang telah dibuat. Sensor ultrasonik yang digunakan berjumlah 1 buah mempunyai 4 kaki yang setiap kaki yang}

setiap kali berhubungan dengan port- port tertentu Vcc terhubung dengan Port Vcc, Ground terhubung ke Port Gnd, Trig yang terhubung ke port B1 dan Echo terhubung ke Port B0. Adapun gambar seperti di bawah ini:

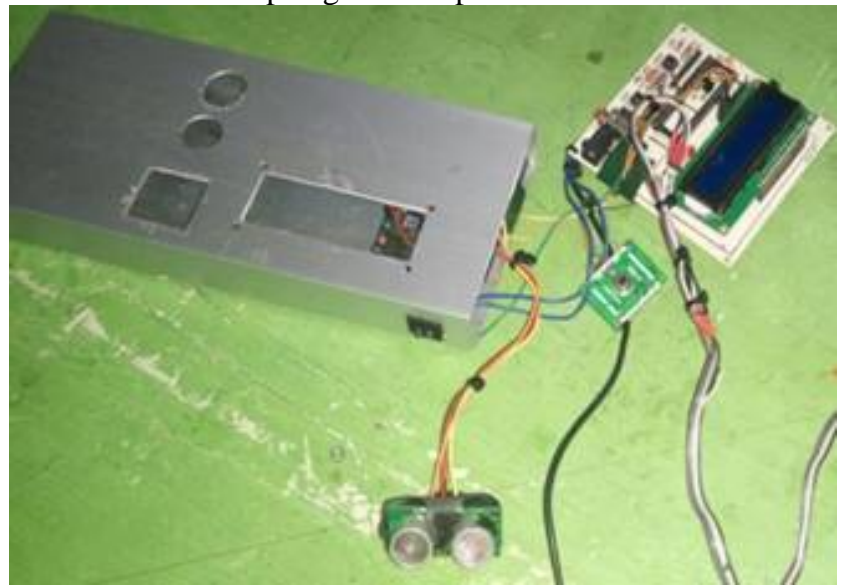

Gambar 6. Tampilan Rangkaian Sensor Ultrasonik Alarm Anti Maling Berbasis Mikrokontroler

\section{2) Tampilan Rangkaian Sensor PIR}

Sensor PIR (Passive Infrared Reciever) merupakan sensor yang digunakan untuk membedakan objek yang berada di dekat alarm . Jarak efektif sensor ini sekitar 6 meter dengan mendeteksi objek dalam bentuk menyebar. Pin Out pada Sensor PIR tehubung dengan port A 0 pada mikrokontroler. Sedangkan Port Gnd terhubung pada port Xtal 1 dan Xtal 2 pada mikrokontroler. Adapun gambar rangkaan tersebut dapat dilihat pada gambar dibawah ini:

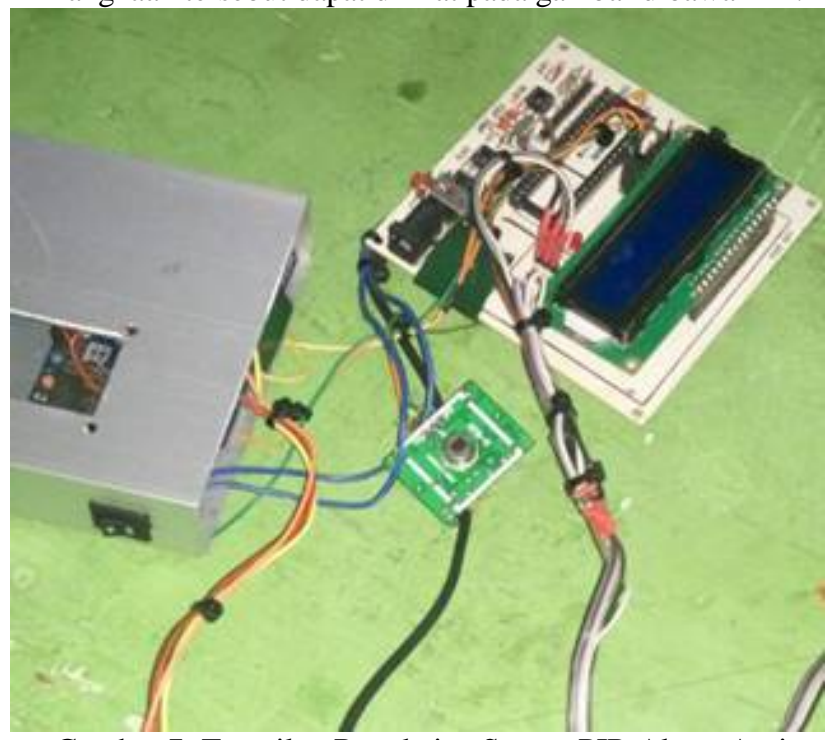

Gambar 7. Tampilan Rangkaian Sensor PIR Alarm Anti Maling Berbasis Mikrokontroler

3) Tampilan Rangkaian Mikrokontroler

Mikrokontroler merupakan bagian penting pada aplikasi pemandu menggunakan sensor ultrasonik pada tongkat tuna netra berbasis mikrokontroler karena 
mikrokontroler adalah otak dari aplikasi ini, dimana semua rangkaian terhubung ke mikrokontroler.

Berikut ini rangkaian mikrokontroler dari tongkat tuna netra berbasis mikrokontroler :

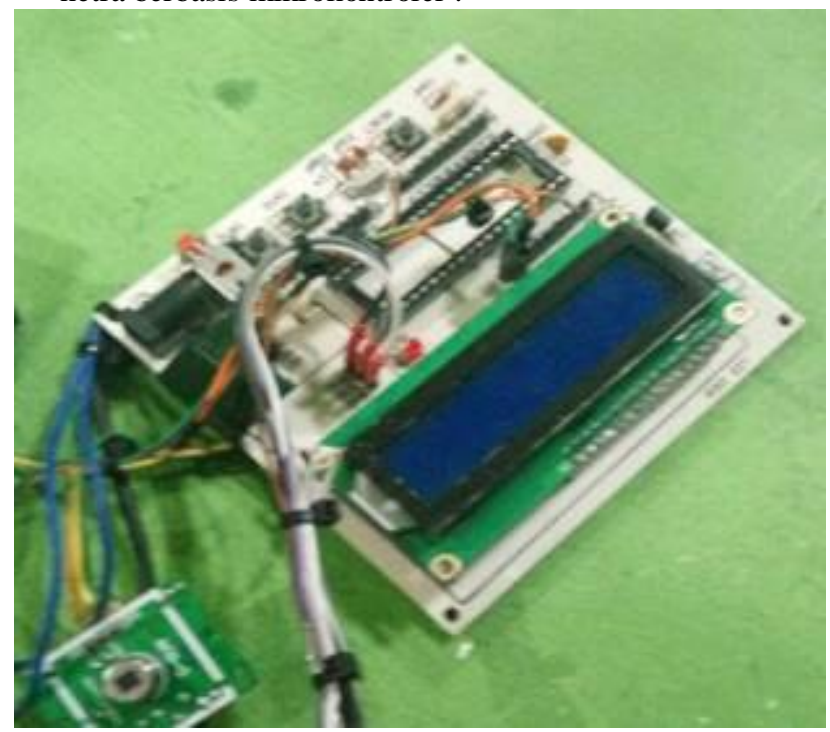

Gambar 8. Tampilan Rangkaian Mikrokontroler

4) Tampilan Rangkaian LCD Monitor Alarm Anti Maling Berbasis Mikrokontroler

LCD Monitor yang dirangkai menggunakan tipe 2 x 16 yaitu 16 baris dan 2 kolom . LCD monitor terhubung ke PORT C pada mikrokontroler LCD monitor akan menampilkan informasi. Status pendeteksian dan pengiriman SMS akan di tampilkan pada LCD tersebut. Adapun seperti gambar dibawah ini:

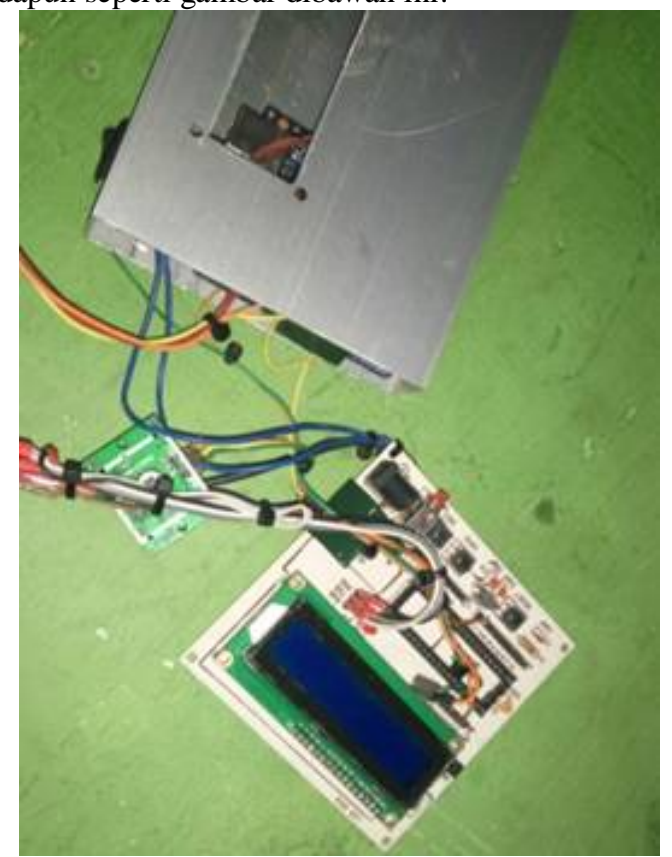

Gambar 9. Tampilan Rangkaian LCD Alarm Anti Maling Berbasis Mikrokontroler
5) Tampilan Rangkaian Modem Fast Track

Pada rangkaian modem fast track yang perlu dirangkai terlebih dahulu adalah sambungan dari mikrokontroler ke converters 232 lalu terhubung dengan port sebagai sambungan ke modem Fast track.

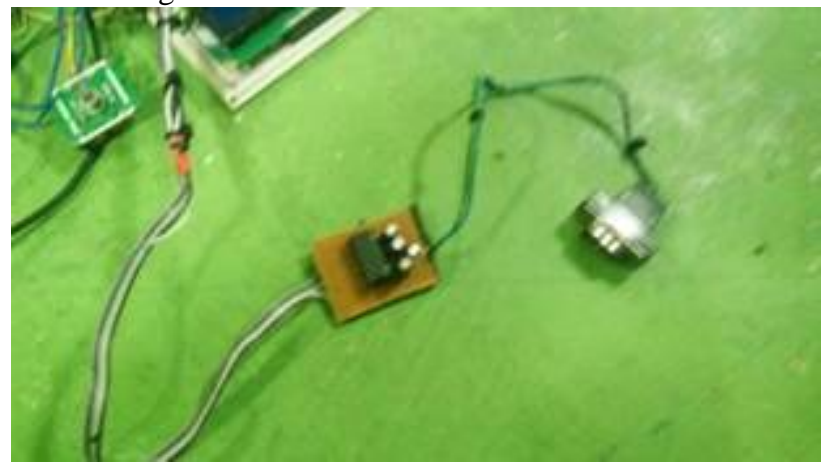

Gambar 10. Tampilan Rangkaian Modem Fast Track

Setelah kita merangkai semua rangkaian satu - persatu maka rangkaian keseluruhan alarm anti- maling sudah selesai. Rangkaian dimulai dari rangkaian sensor ultrasonik, rangkaian sensor PIR, serta rangkaian modem yang semuanya terhubung pada mikrokontroler ATmega 8535 sehingga siap dimasukan kedalam kotak Alarm yang telah dibuat sebelumnya.

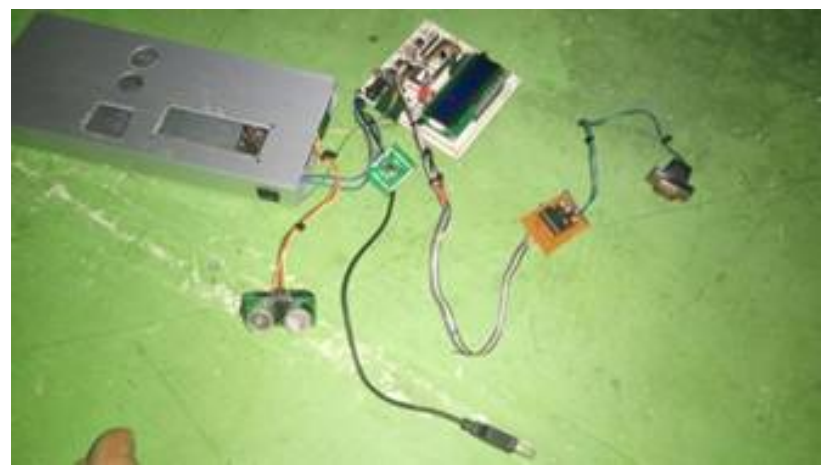

Gambar 10. Tampilan Keseluruhan Rangkaian Alarm Anti Maling Berbasis Mikrokontroler

\section{Kesimpulan}

Berdasarkan hasil pengujian alarm anti-maling berbasis mikrokontroler, maka dapat diambil kesimpulan sebagai berikut:

- Alarm mampu mendeteksi objek dengan tepat dan hanya mengukur jarak terhadap objek yang terdeteksi sebagai manusia.

- Mampu bekerja selama 24 penuh tanpa pengawasan.

- Cara pengoperasian yang mudah.

- Mampu mengirimkan SMS dan melakukan panggilan ke ponsel pengguna sebagai peringatan tanda bahaya percobaan pencurian. 


\section{DAFTAR PUSTAKA}

[1] Atmaja, Frendy Yudha. 2010. Otomatisasi Kran Dan Penampung Air Pada Tempat Wudhu Berbasis Mikrokontroler. Surakarta. Tugas Akhir Program Diploma III Ilmu Komputer Fakultas Matematika Dan Ilmu Pengetahuan Alam Universitas Sebelas Maret.

[2] Bejo, Agus. 2008. C \& AVR Rahasia Kemudahan Bahasa C Dalam Mikrokontroler ATMega 8535. Yogyakarta : Grahallmu.

[3] Budiharto, Widodo. 2004. Interfacing Komputer Dan Mikrokontroler. Jakarta: Elek Media Komputindo.
[4] L.Wadhana. 2006. Belajar Sendiri Mikrokontroler AVR Seri AT Mega 8535, (Online), (http://Openlibrary.telkomuniversity.ac.id, diakses pada tanggal 29 Mei 2016).

[5] MA.Heryant, H Suprijono. 2011. Aplikasi Gelombang Ultrasound Pada Tongkat Putih Untuk Peringatan Dini Bagi Penyandang Tuna Netra, (Online), (http://publikasi.dinus.ac.id, diakses pada tanggal $29 \mathrm{Mei}$ 2016).

[6] Sumardi. 2013. Mikrokontroler Belajar AVR Mulai Dari Nol Yogyakarta: Grahallmu.

[7] Susilo, Joko. 2015. Aplikasi Pompa Air Otomatis Berbasis Sensor Ultrasonik. Pangkalpinang. Tugas Akhir Program Strata 1 Teknik Informatika Sekolah Tinggi Manajemen Informatika Dan Komputer Atma Luhur. 